Provided for non-commercial research and education use. Not for reproduction, distribution or commercial use.

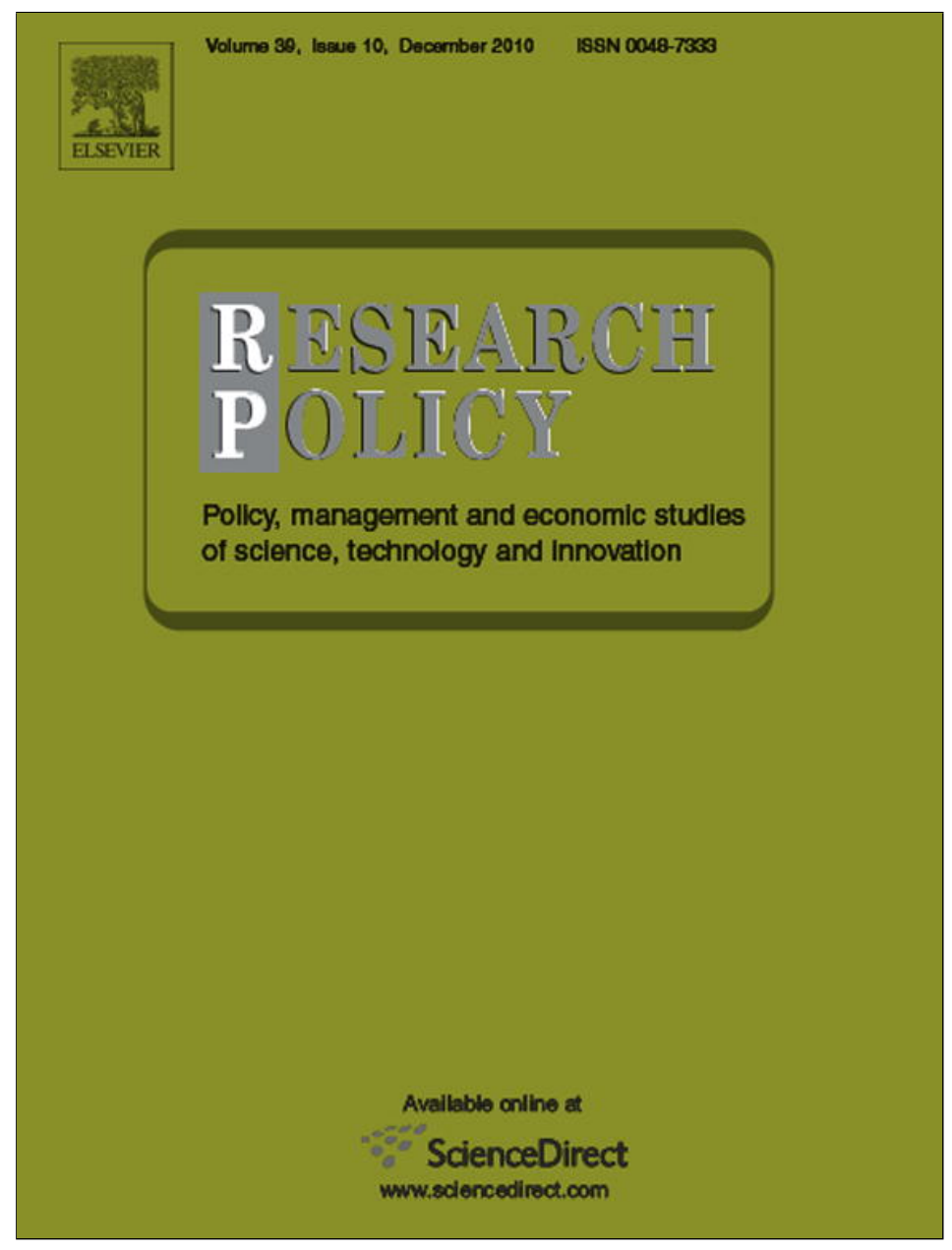

This article appeared in a journal published by Elsevier. The attached copy is furnished to the author for internal non-commercial research and education use, including for instruction at the authors institution and sharing with colleagues.

Other uses, including reproduction and distribution, or selling or licensing copies, or posting to personal, institutional or third party websites are prohibited.

In most cases authors are permitted to post their version of the article (e.g. in Word or Tex form) to their personal website or institutional repository. Authors requiring further information regarding Elsevier's archiving and manuscript policies are encouraged to visit:

http://www.elsevier.com/copyright 


\title{
The innovation-economic growth nexus: Global evidence
}

\author{
Iftekhar Hasan $^{\mathrm{a}, \mathrm{b}, *}$, Christopher L. Tucci ${ }^{\mathrm{c}}$ \\ ${ }^{a}$ Rensselaer Polytechnic Institute, Lally School of Management \& Technology, Troy, NY 12180, United States \\ ${ }^{\mathrm{b}}$ Bank of Finland, Helsinki, Finland \\ c EPFL College of Management of Technology, Ecole Polytechnique Fédérale de Lausanne, Station 5, CH-1015, Lausanne, Switzerland
}

\section{A R T I C L E I N F O}

\section{Article history:}

Received 29 July 2008

Received in revised form

12 November 2009

Accepted 12 July 2010

Available online 16 August 2010

\section{Keywords:}

Innovation

Economic growth

Patents

\begin{abstract}
A B S T R A C T
This paper extends the line of research attempting to link innovation to economic growth by addressing some unexplored questions. Using global patent data, this paper empirically investigates the importance of both the quantity and quality of innovation on economic growth, controlling for past measures of inventive inputs. Moreover, our research examines how innovation inputs can be translated into per capita growth under the various economic structures and stages of economic development. Based on a sample of 58 countries for the period 1980-2003, our empirical results indicate that countries hosting firms with higher quality patents also have higher economic growth. Furthermore, we have some evidence that those countries that increase the level of patenting also witness a concomitant increase in economic growth.
\end{abstract}

(c) 2010 Elsevier B.V. All rights reserved.

\section{Introduction}

Economic growth, especially its long-run sustainability, has long been a focal point of academic researchers and policy makers. Numerous attempts have been made to provide a long list of factors that may have an impact on economic growth. Pioneering work on endogenous growth by Romer (1986), Lucas (1988) and others emphasizes the role of knowledge as an input to production. In their models, it is the technological advancement and industrial innovation that drive long-run growth (Grossman and Helpman, 1994).

In addition, since at least the time of Schumpeter (1932), the process of industrial innovation has been seen as important to the economy. When Schumpeter wrote about innovation, he clearly intended to emphasis not only the "destruction" aspect of creative destruction, but the "creative" part as well (Freeman and Soete, 1997). In other words, Schumpeter was an early thinker on the relationship between industrial innovation and economic growth at a more macro level.

Since then, in the field of economics, research on endogenous growth theory sparked many empirical studies exploring how and to what extent innovation might contribute to economic growth. Empirical evidence taken as a whole points to the fact that innovation tends to make significant contributions to growth, and there are also significant spillover effects of innovative activities

\footnotetext{
* Corresponding author. Tel.: +1 5182762525.

E-mail addresses: hasan@rpi.edu (I. Hasan), christopher.tucci@epfl.ch (C.L. Tucci)
}

(Cameron, 1998). In this paper, we aim to extend this line of research by arguing that not only the quantity but also the quality of innovation matters in promoting economic growth. Furthermore, we are interested in investigating whether the effects of innovation on economic growth largely depend on the economic structure and stage of development in different countries.

In the models of Romer $(1986,1990)$ and Stokey (1995), among others, industrial innovation activities are an important determinant of economic growth due to their direct impact on the production process and also due to positive externalities. Scholars have also argued that "national innovation systems" - which include aspects of how intellectual property is protected and how research and development (R\&D) is funded - is a major contributor to innovation activities (Nelson, 1993; Freeman and Soete, 1997).

Though technological change forms the engine of long-run growth, accumulation of other types of capital will still play an independent role during a transitional phase (Grossman and Helpman, 1994). This notion implies that how innovation activities can be translated into different rates of growth is closely linked to the variation of economic structures and policies (Grossman and Helpman, 1994). In this paper, we make use of global patent databases to construct measures of innovation and empirically examine the proposed research questions. We use a panel of data to investigate the potential relationship between measures of the innovations, both quantity and quality, and economic growth. Based on a sample of 58 countries for the period 1980-2003, our empirical results indicate that those countries that increase the level of patenting also witness a concomitant increase in economic growth. Furthermore, we provide some evidence that countries hosting firms with higher quality patents also have higher economic growth. 
The rest of this paper is organized as follows. Section 2 provides a brief review of related literature. Section 3 explains our data collection and discusses some methodology issues. Section 4 presents our empirical results. In Section 5, we summarize, discuss and conclude.

\section{Literature review}

Questions about the sources of economic growth have fascinated economists for many years. Neoclassical growth models posit that the rate of return on investment is a decreasing function of per capita capital stock, and per capita outcomes across different countries should converge to a steady state in the absence of exogenous technological change. However, these predictions are somewhat inconsistent with observations from the real world. Without a doubt, technological advancement has become a major factor behind economic growth by, among other factors, providing new means to combine raw materials. It is unrealistic to attribute all the unexplained part of economic growth to exogenous technological shocks.

Several studies attempt to incorporate industrial innovation into models to explain economic growth. Romer (1986) showed that knowledge with increasing marginal productivity could be an input in explaining long-run growth. In a competitive economic environment, intentional investments in innovation activities are motivated by market incentives (Romer, 1986; Aghion and Howitt, 1992; Stokey, 1995). Treating technological changes as endogenous, Romer (1990) presented a model of the growth rate being determined by the stock of human capital, even though new technology is assumed to be no better than old (horizontal product innovation). In contrast, Aghion and Howitt (1992) developed a model in which vertical innovations make existing products obsolete, becoming the underlying source of growth through a process similar to creative destruction in which demand increases for the superior product, more than compensating at the macro level for the reduction in competitiveness of the product based on the old technology.

The innovation process has its own externalities. The accumulation of technological advancement enlarges the knowledge base and makes sequential innovations available (Stokey, 1995). Knowledge flows and technological spillovers across economic agents benefit all firms including rival firms as well (Griliches, 1992). Even when technological spillovers do not exist, an agent does not appropriate all the social gains from her innovation unless she can price-discriminate. In addition to the efforts made by profit-maximizing firms, academic research funded by public resources in universities and other institutions provides substantial inputs and spillovers into the innovation process (Fagerberg, 1994).

Innovation activities do not only directly influence economywide productivity, but also promote economic growth through spurring new business formation, which further promotes employment growth and other outputs (Kirchhoff, 1994; Wennekers, 1999). Innovation encourages and facilitates entrepreneurs to create new organizations in order to enter certain industries characterized by an entrepreneurial technological regime (Audretsch, 1995). This indirect mechanism has been supported by empirical evidence (Francis et al., 2007; Kirchhoff et al., 2007).

Summarizing the above, innovation can be considered important for potential economic growth. So what evidence do we have that it is linked to growth, and at what levels of analysis? Various studies have been conducted at the level of individual firms, industries, as well as countries. Cameron (1998) surveys the existing literature on this topic and concludes that the majority of these studies find a positive link between innovation and some measures of output (Mansfield, 1980; Griliches and Mairesse, 1986).

Meanwhile, many other studies attempt to investigate the spillover effects of innovation. For example, Coe and Helpman (1995) and Bayoumi et al. (1999) have documented that international trade can greatly raise a country's total factor productivity. There are many reasons for this, but one factor could very well be knowledge transfer due to international trade. However, there is a limitation for such spillovers across countries. Audretsch and Feldman (1996) find that innovation spillovers tend to be localized in the sense that industries with a prevalence of knowledge spillovers have a high propensity to be clustered. For example, there may be important barriers to knowledge flow even between European countries (Maurseth and Verspagen, 2002; Bottazzi and Peri, 2003).

The above leads to the following two hypotheses:

H1. The higher the level of innovative activity, the higher the rate of economic growth in an economy.

H2. The higher the quality of innovative activity, the higher the rate of economic growth in an economy.

\section{Methods}

How to precisely measure innovation is an important issue in the empirical endeavor to explore the effect of innovation on growth. In the existing literature, research and development (R\&D) expenditures are widely used as a proxy for innovation partly because of the availability and reliability of data (Griliches, 1980; Mansfield, 1980; Audretsch and Feldman, 1996; Goel and Ram, 1994). Many other researchers intend to use alternative measures of innovation such as patenting activities. Despite several major problems associated with using patent data (see below), there are at least three reasons why patent statistics can be an important economic indicator of innovation (Griliches, 1990) and thus the fascination of academic economists with such statistics. First, patenting databases are generally more available and richer in the sense that patents are public documents with detailed information on the background of assignees and their activities. Second, patents can be viewed as the output of an inventive process and link together R\&D activities and productivity. Finally, using patent data, one is able to construct both quantitative and qualitative measures of innovation activities, and researchers may under certain circumstances trace the citation records to better gauge the spillover effects of technology changes. ${ }^{1}$ Of course, there are also problems associated with using patents as innovation indicators; see Section 5 for more detail on these issues.

To our best knowledge, there are very few comprehensive studies examining innovation and economic growth in a crosscountry setting using patent data (Maurseth and Verspagen, 2002; Bottazzi and Peri, 2003). In this paper, we try to address this need by constructing a cross-country sample, and address some unanswered questions with the help of a recently available global patent database. In particular, we attempt to add knowledge to the existing literature by focusing on the effects of both quantity and quality of innovation on economic growth. Additionally, we explore the impact of innovation at different stages of development for different countries.

Empirical research using cross-country data has provided much insight on the role of institutions in promoting economic growth

\footnotetext{
1 Note: the structure of the US national innovation system in which the applicants supply many prior art references leads to this interpretation. However, it should be noted that in the European Patent Office, the examiners provide the prior art citations and thus any knowledge flow interpretations are unwarranted (Harhoff et al., 2008).
} 
Table 1

Summary statistics.

\begin{tabular}{|c|c|c|c|c|c|}
\hline Variable & $N$ & Mean & SD & Min & Max \\
\hline Annual growth rate in per capita real GDP - GDPPCGR & 1162 & 0.02031 & 0.04753 & -0.19730 & 0.26550 \\
\hline Gross private capital formation to GDP - GCAPFORM & 1162 & 0.23426 & 0.09559 & 0.03450 & 0.68000 \\
\hline Government consumption to GDP - GCONGDP & 1162 & 0.19010 & 0.07523 & 0.06530 & 0.54450 \\
\hline Exports to GDP - EXPGDP & 1162 & 0.39678 & 0.27090 & 0.05060 & 1.70000 \\
\hline Literacy rate for labor force - LITRATE & 1162 & 0.89633 & 0.14516 & 0.44170 & 0.99730 \\
\hline Foreign direct investment to GDP - FDIGDP & 1162 & 0.02982 & 0.05718 & 0.00000 & 0.79340 \\
\hline Technology index - TECHINDX & 1162 & 0.02906 & 0.00453 & 0.01170 & 0.03570 \\
\hline Research and development (R\&D) expenditure to GDP - RNDGDP & 1162 & 1.27869 & 0.93115 & 0.01550 & 5.08010 \\
\hline Total number of patents granted to R\&D expenses - TPATR & 1162 & 0.00870 & 0.04774 & 7.74863E-9 & 0.87655 \\
\hline Proportion of patents granted in the USA & 1162 & 0.11392 & 0.47591 & 0.0002528 & 8.50000 \\
\hline Residual of the estimation of TPATR on RNDGDP - MAGIC & 1162 & 0.01679 & 0.01309 & -0.02760 & 0.09810 \\
\hline
\end{tabular}

The table presents summary statistics of the variables used in this paper. $N$ refers to country-year observations for 58 countries during the sample period $1980-2004$. GDPPCGR: annual growth rate in per capita real GDP is the change in the natural logarithm of real per capita GDP; GCAPFORM: gross private capital formation of a given sample year; GCONGDP: government consumption to GDP is the expenses in a given year by the government to GDP; EXPGDP: exports to GDP are defined as the ratio of total exports to GDP; LITRATE: literacy rate of the labor force (secondary education); FDIGDP: foreign direct investment to GDP is the total FDI incoming to the country in a given year to the GDP; TECHINDX: technology index is an index developed from a number of variables: electric power consumption (kWh per capita), fixed line and mobile phone subscribers (per 1000 people), personal computers (per 1000 people), radios and telephone sets (per 1000 people); RNDGDP: total R\&D to GDP is the total research and development expenditure at the country level to GDP; TPATR: total number of patent granted as a proportion of million dollars of research and development expenditure; USAR: ratio of patents granted in the USA as a proportion of total patents granted by the country in a given year; MAGIC is the residual from the regression estimate of the variable TPATR on RNDGDP.

(King and Levine, 1993; Knack and Keefer, 1995; Rousseau and Wachtel, 2000; Wachtel, 2001). However, as mentioned above, very few cross-country studies are associated with any potential association between direct measures of innovation and growth.

\subsection{Data sources}

The data set was constructed from a number of sources. We started with the US Patent database available from the National Bureau of Economic Research and the PATSTAT database encompassing international patents, and examined the country of both the inventor and the assignee. Work by Jaffe et al. (1993) and Jaffe and Trajtenberg (1999) suggest that patent data can be considered one measure of innovation. Unlike an exogenous technological shock, intentional investments in $R \& D$ are driven by profit incentives. Among other forms of protecting intellectual property, economic agents are likely to file patents to protect the property rights generated by their private investment in R\&D. Moreover, patent documents themselves contain references to prior patent documents and influential inventions tend to be heavily cited. Patent citations can thus in some circumstances (see footnote 1) be interpreted as knowledge flows from one invention to another (Jaffe et al., 1993; Duguet and MacGarvie, 2005), and can be used to identify those innovations with breakthrough impact. Therefore, patent data may allow researchers to gauge the quantity of invention as well as something akin to the "quality" of innovations. In this particular case, we combine observations of such inventive activity from countries as described below, so we have one observation per country per year.

GDP and other macroeconomic data for the countries were obtained from the World Development Index (WDI), while R\&D figures for individual firms inside countries were found in the WorldScope database.

\subsection{Variables}

Descriptive statistics and variable names are shown in Table 1, and Table 2 presents the correlation matrix of the variables. The mean real GDP growth rate is $2.03 \%$ and the standard deviation twice as large. The explanatory variables also show a great deal of variation. Their range indicates that there are outlier observations though no effort was made to exclude such observations other than to include fixed effects for countries in some regressions. The simple correlations with the growth rate of GDP are all modest. The level of GDP is highly correlated with capital formation and moderately correlated with FDI, RNDGDP, and TPATR (defined below). Interestingly, the correlation of the level of GDP is not highly associated with the Technology Index (also defined below).

\subsubsection{Dependent variables}

Our dependent variable, growth, is the growth rate of real annual per capita GDP in the country. The variable is operationalized as the change in the log of real per capita GDP. Real per capita GDP is defined as per capita GDP deflated to the base year of 1980 .

\subsubsection{Independent variables}

A major challenge in this paper was to determine what an appropriate proxy was for innovation. In the past, scholars have used R\&D as a measure of innovative activities and in firm-level studies argued that R\&D is more of an input to the actual output (Schmookler, 1966). Teece (1986) proposes that "an innovation consists of technical knowledge about how to do things better than the existing state of the art." One criterion for obtaining a patent in many countries is "commercial applicability," which points to the need for patent protection as a kind of insurance policy against appropriation (Hall et al., 2001). In the United States, one requirement is that patents must be "useful" (hence the term "utility", see United States Code, 1952). The combination of utility, nonobviousness, and novelty is required for a patent to be granted in the US, and in several US industries (but certainly not all, see Section 5 ), patenting is regarded as the most important form of protecting inventions (Cohen et al., 2000). Further, counts of the number of patents have been used as a proxy for innovation (e.g., Ahuja and Katila, 2001) with recognition of their limitations (see below).

We employ both R\&D and innovation variables in our specifications. The actual R\&D variable considered, RNDGDP, is the total real research and development expenditure in the country as a ratio to the GDP of the country. In cases where such an R\&D figure was not available, e.g., Egypt, we simply summed the R\&D spending of all firms reporting in the WorldScope database. Second, we took the actual number of patents granted to a respective country regardless of where the patentee actually resided as long as the company was headquartered in the country. In other words, if Siemens were the assignee of a patent in the US patent database, regardless of whether the lab itself was in China, the patent would be assigned to the country Germany, which is where Siemens is headquartered. In our paper we operationalize the variable by taking the number of patents granted per million dollars of R\&D. 


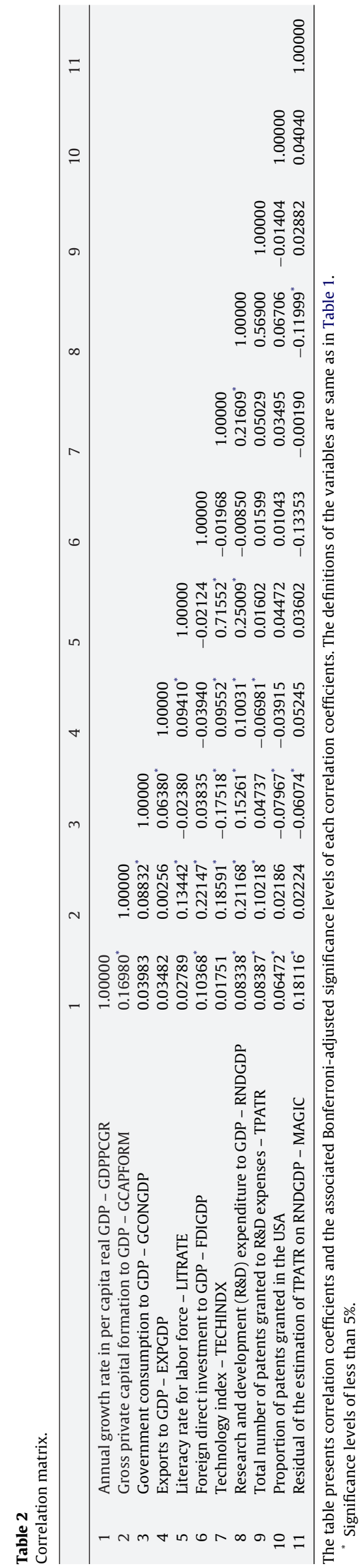

Next, we focus on the "quality" aspect of the innovations. An often-used measure would have been to get a quality measure based on Hall et al.'s (2001) method, i.e., forward citations of each patent relative to other patents in its technology class in that year, aggregated up to the country level. We were somewhat successful in gathering the citation numbers for most of the sample countries; however, after careful evaluation, we could not defend the reliability of the variable for the full sample (see "robustness checks"). We therefore utilized two alternative quality indicators, as explained below.

First, we examined USAR, defined as the Ratio of Patents Granted in the USA as a proportion of total patents granted by the country in a given year, as one proxy for innovation quality. ${ }^{2}$ For example, the country of Brazil granted 26,582 patents in the year 2000 based on their own patent office statistics from PATSTAT, while Italy granted 28,970 . We then examine how many patents were assigned to Brazil and Italy, and granted in the US in that same year, in this case 98 and 1715, respectively. Thus USAR for Brazil in 2000 would be equal to $0.37 \%$, while USAR for Italy in 2000 would be $5.9 \%$. Our assumption is that the patent applications of non-US firms granted in the US are usually significant innovations and represent relative quality. There are several possible explanations for why firms would patent in the US: the "unreliability" of their own national innovation system, for prestige purposes, and for trade/exporting/sales (direct commercial) purposes. We attempt to tease apart these explanations in the section on "Robustness".

We also estimate another quality variable, which we call Magic in the Air (MAGIC) by regressing RNDGDP on TPATR (with and without patent stock $\mathrm{k}^{3}$ at the end of the year preceding the period) and taking the residual from this regression. Our perspective here is that while it is plausible that innovation is a product of R\&D, it is also possible that innovation may come to an organization or to a country beyond the proportion of R\&D spending. Kortum and Lerner (1999) note that during the period between 1963 and the late 1980 s, both $R N D G D P$ and patenting quantity increased dramatically, but in the 1990s RNDGDP actually fell in most countries while patenting quantity continued to explode. Thus R\&D intensity may not fully reflect all innovation activities. This might be explained by several factors. One might be that research productivity changes over time in a way described as early as 1964 by Rosenberg \& Spencer in which they outline changes in the management of R\&D that might make it more productive and commercially oriented. Another explanation might be knowledge spillover effects that could act as a "multiplier" on R\&D expenditures diffused through labor force mobility, globalization of companies, or supply chain "leakage:" e.g., sharing of information with suppliers who also serve other customers (Tucci et al., 2005). How much innovation is coming from R\&D inputs leading to patents and how much of this inventive activity may also be a product of changes in market structure or competitive posturing by firms. If the market is competitive, some firms may want to create entry barriers by erecting patent "thickets" around certain technologies (Shapiro, 2001). Diffusion and popularization of the Internet may have added to this effect through the ability of firms to serve markets in a wider geographical area, thus leading to more competition (Afuah and Tucci, 2003), thus giving firms incentives to search out other methods of keeping competitors at bay, including via intellectual property means.

\footnotetext{
${ }^{2}$ Even though there is a debate in the literature on the standards of the US Patent \& Trademark Office (i.e., are they too "lax" or "aggressive" in granting patents?), we feel the correct comparison group is not US firms patenting in the US, but non-US firms patenting both at home and in the US. We argue that due to the motivations developed below (and suggested by an anonymous referee), the patents filed and granted in the US would tend to be of higher quality than those patented solely at home, regardless of whether the US is too aggressively granting patent rights.

3 We would like to thank one of the anonymous referees for this suggestion.
} 


\subsubsection{Control variables}

We use a number of independent variables popularly used in the literature in cross-country growth estimations. Initial GDP Values are useful to understand the relative changes from sample countries exhibiting a wide range of development stages. Capital Formation (GCAPFORM) and Literacy Rate (LITRATE) are common proxies for capital and human capital, respectively, of the countries. So is Government Spending (GCONGDP). Exports and Foreign Direct Investments (FDI) are considered crucial to economic growth. We also include a Technology Index variable to control for the technological sophistication of the respective countries. This index was developed from a number of variables: electric power consumption ( $\mathrm{kWh}$ per capita), fixed line and mobile phone subscribers (per 1000 people), personal computers (per 1000 people), radios and telephone sets (per 1000 people).

\subsection{Statistical approach}

Our model builds on the approach to growth equations introduced by Barro and Levine (1991). As mentioned earlier, the baseline equation includes crucial variables such as the convergence effect (log of initial real GDP), the human capital investment variable (literacy) and the export ratio (openness). We also add a few other relevant variables. The baseline regression provides a reasonable framework for analyzing growth in a cross-country environment. We then add measures of research and development and innovation (patent) proxies. We start with OLS regressions with robust standard errors. We then follow the same procedure except the dependent variable takes 3-year averages of growth as the measure of country growth. All estimates control for year and country fixed effects. It is well known that OLS estimates are biased and inconsistent when there are dynamic effects and simultaneities in the specification. To account for these effects, the recent literature (e.g., Levine et al., 2000) has employed the Generalized Method of Moments (GMM) technique developed by Arellano and Bond and others for panel estimation and we utilize this technique as well.

The Arellano-Bond GMM technique is specifically designed to address the econometric problems induced by unobserved groupspecific effects and joint endogeneity of the explanatory variables in lagged-dependent-variable models, such as growth regressions. Similar to Levine et al. (2000), we employ an augmented GMM procedure outlined in Arellano and Bover (1995) and developed in Blundell and Bond (1998), which combines the regression in differences with the regression in levels (see Bond, 2002). In the Blundell and Bond GMM estimator, the instruments for the regression in levels are the lagged differences of the corresponding variables, and the instruments for the regression in differences are the lagged levels. ${ }^{4}$ These are appropriate instruments under the additional assumption that there is no correlation between the differences of these variables and the country-specific effects, while correlation between levels of the right-hand side variables and the countryspecific effect is allowed. There are two tests to test the validity of the instruments, as suggested by Arellano and Bover (1995) and Blundell and Bond (1998). The first is the Sargan test or Hansen test of over-identifying restrictions, which tests the overall validity of the instruments by analyzing the sample analog of the moment conditions used in the estimation process. ${ }^{5}$ The second test is the

\footnotetext{
${ }^{4}$ More specifically, we use the two-step GMM instead of one-step because two-step is asymptotically more efficient, meanwhile we also compensate for the potentially downward biased two-step standard errors by making a finite-sample correction to the two-step covariance matrix derived by Windmeijer (2005).

${ }^{5}$ As for the over-identifying restrictions, we conduct the Hansen test instead of the Sargan test, because the Sargan statistic is not robust to heteroskedasticity or autocorrelation while the Hansen statistic, which is the minimized value of the twostep GMM criterion function, is robust.
}

autoregressive (AR) test, which examines the hypothesis that the error term is not serially correlated in both the difference regression and the system difference-level regression. By construction, the differenced error term is allowed to be first-order serially correlated, but the second-order serial correlation of the error term will violate the assumption of the GMM procedure.

We also present equations with annual data estimated with the Blundell and Bond dynamic panel data estimation technique, i.e., the two-step system GMM estimations. We treat all of the financial and institutional variables as endogenous and the baseline variables as exogenous. As described above, the instruments for the regression in levels are the lagged differences of the corresponding variables, and the instruments for the regression in differences are the lagged levels. We also report the Wald Chi-square test statistic, the $p$-value of the Hansen test, and the $p$-value of the $\operatorname{AR}(1)$ and $\operatorname{AR}(2)$ tests. In all instances, the $p$-values of the Hansen test and the $\operatorname{AR}(2)$ test are larger than 0.05 , which indicates failure to reject the null hypotheses of over-identification and second-order serial correlation of error terms. In other words, the specification tests support the validity of the instruments, thus bolstering the interpretation of the estimated coefficients as being free from endogeneity bias.

Another approach to the endogeneity problems commonly found in the growth literature is to use a multi-year average growth rate as the dependent variable and to use initial year values for all the independent variables. For example, Levine et al. (2000) use non-overlapping 5-year average data in their GMM specifications. Similarly, we also estimate but do not report the GMM estimations based on 3-year average growth rates due to the similarity of the results with the annual data. These regressions are available upon request. All these regressions meet the specifications tests, and there is no evidence of second-order serial correlation. Furthermore, the regressions pass the Hansen specification test.

\section{Results}

Tables 3-6 show the results of our regression analyses. Each column in the table represents a different model. Let us begin with Table 3, which shows results for per capita GDP growth in relation to the innovation and growth variables. Table 3 is grouped into three different groups, with three models per group. As discussed above, the first six rows of the table contain control variables considered to be important in the economic growth literature, plus the control variable Technology Index, plus fixed effects for Year and Country, as shown in Models 1, 4, and 7. The first three models are for the entire combined sample of all 58 countries over the 25 -year period. The second and third set of three models split the sample along the lines of income level of the countries, with Models 4-6 showing the results for upper-income countries and Models 7-9 showing results for the lower-income countries.

Each of the regression tables shows the same model specifications. Absolute values of $t$-statistics are reported in parentheses in all the regression tables and ${ }^{*},{ }^{* *},{ }^{* * *}$ indicate significance at the $10 \%, 5 \%$ and $1 \%$ levels respectively. The first equation reported in Table 3 column 1 reports the baseline model. The second equation shows the baseline growth model augmented by the two measures of innovation related variables, RNDGDP (Research and Development as a proportion of GDP) and PATR (Patents Granted per Million of RED Spending). Similarly, equation three (column 3) introduces a different proxy for innovation (MAGIC) that takes the residual from a separate regression where TPATR is regressed on RNDGDP. The next six columns follow the same order for the two sub-samples. We also estimate a similar regression excluding the USA from the sample (not reported, but with highly similar results). We see that the baseline regression provides some evidence of a convergence 


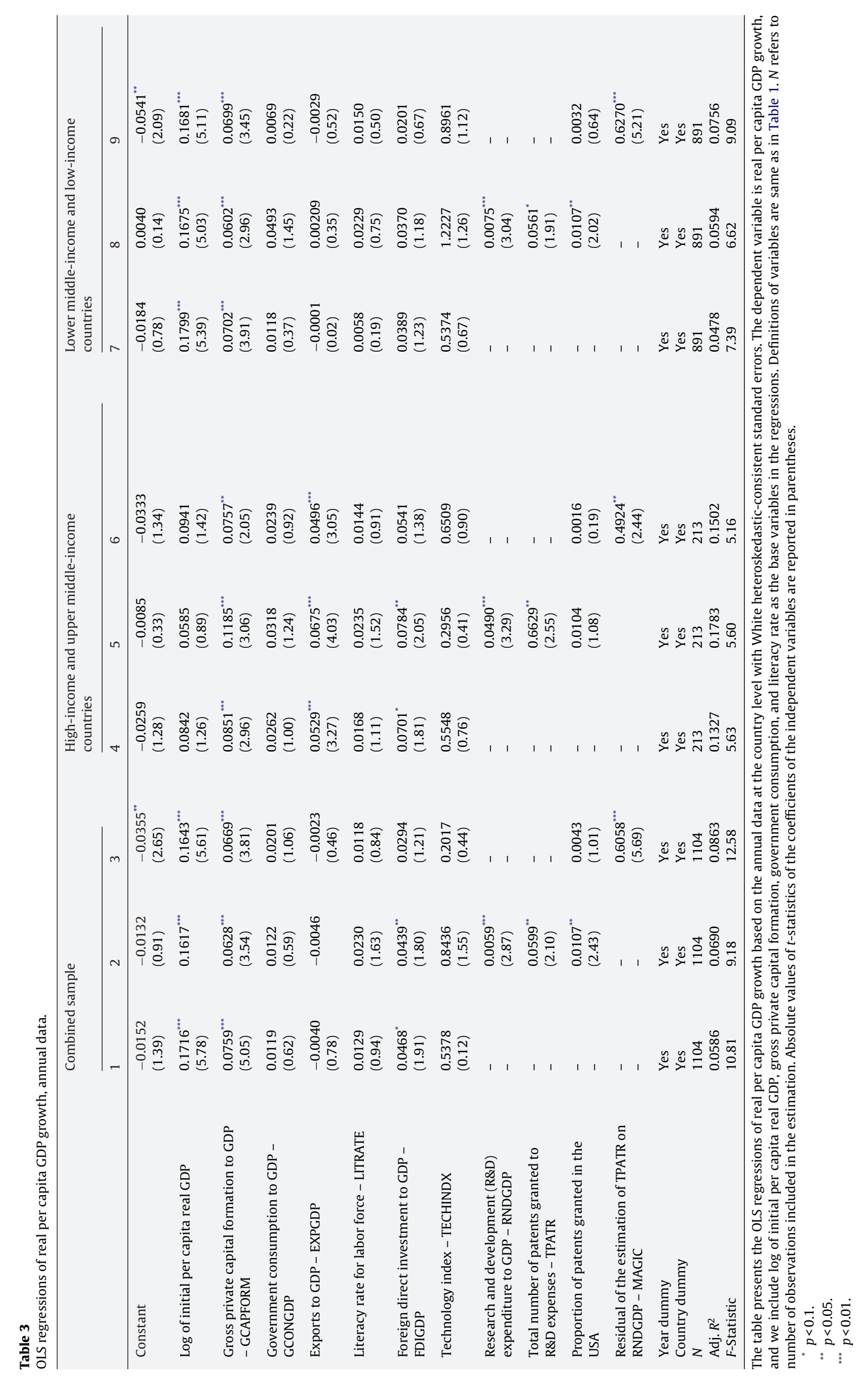




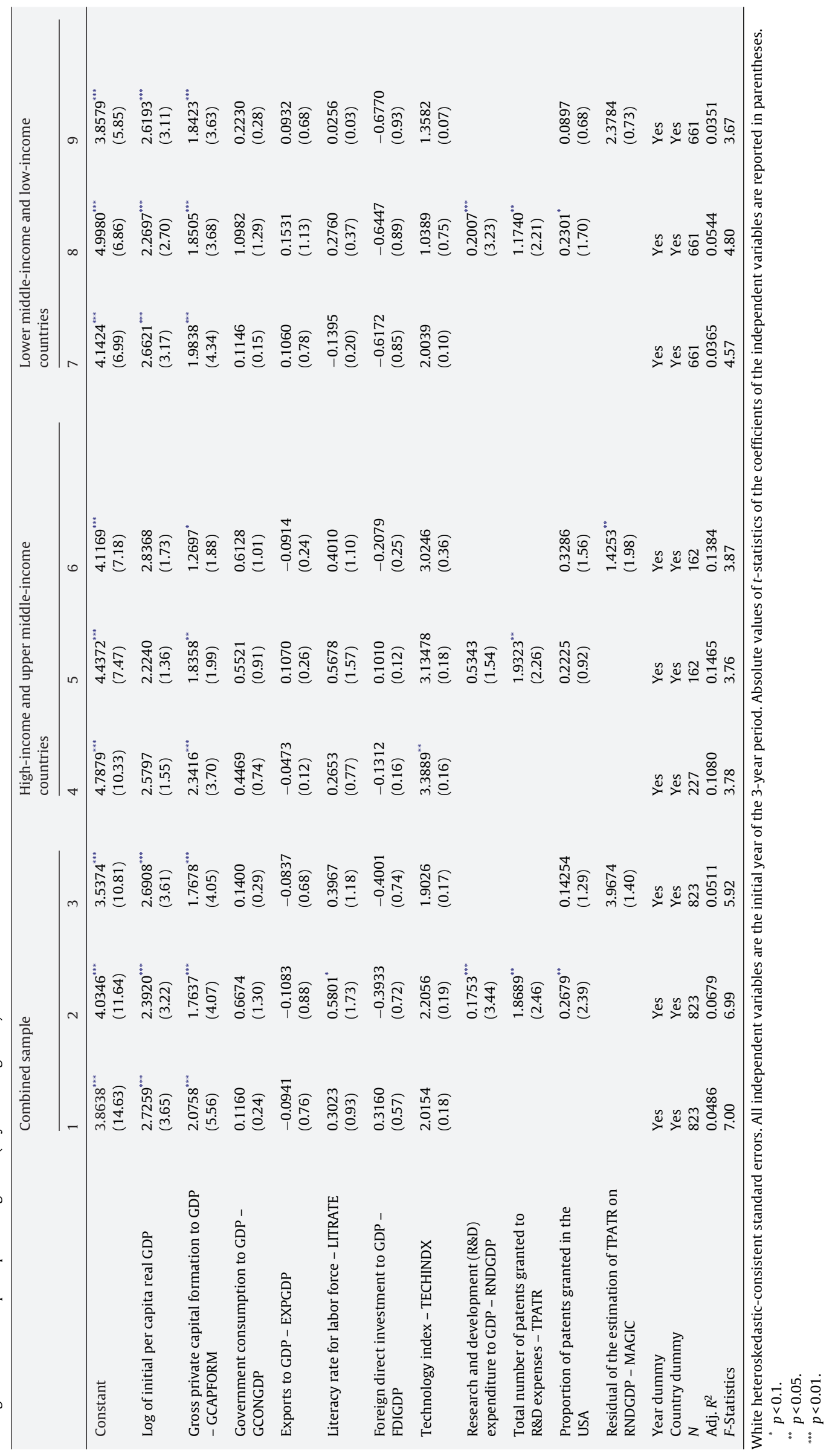




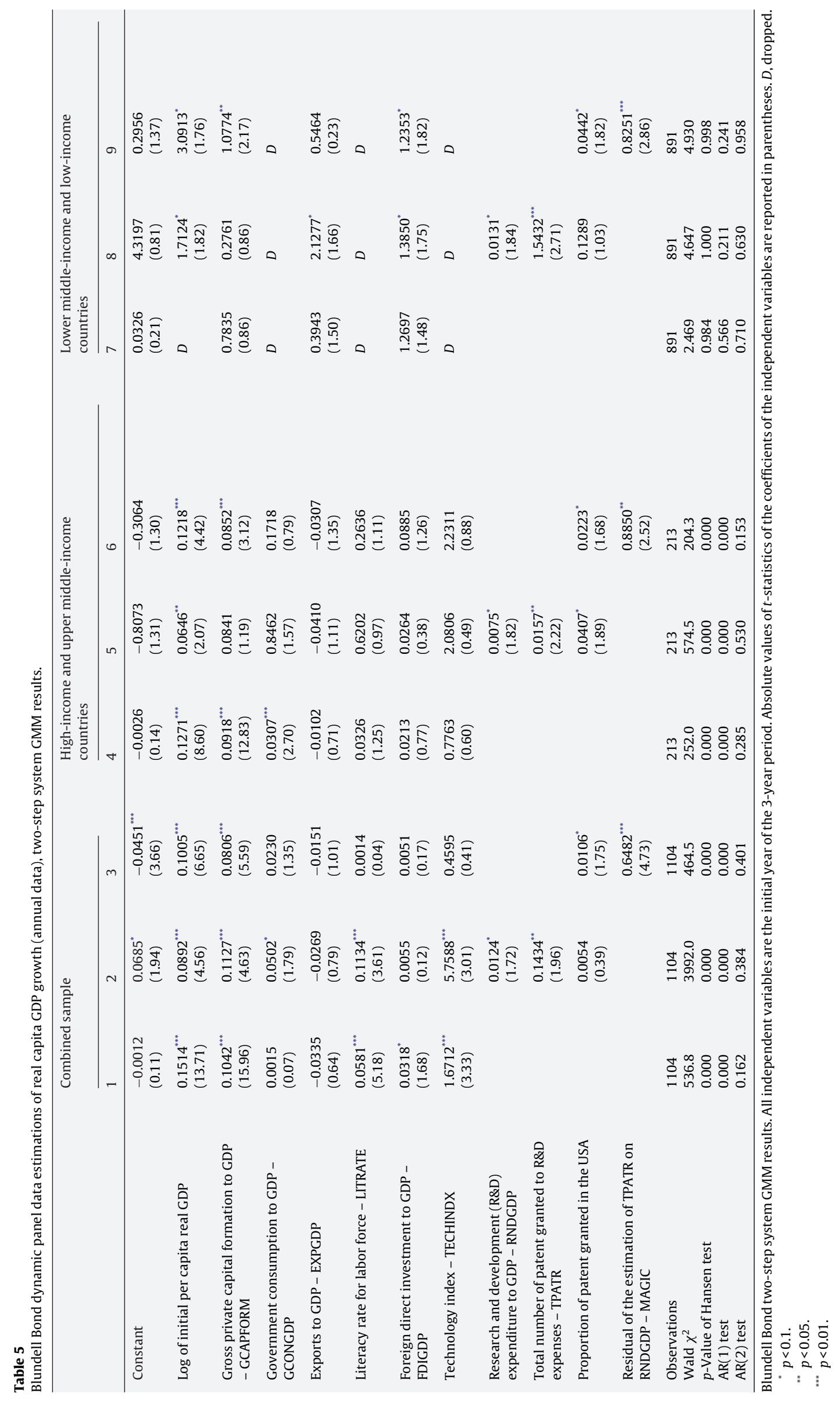




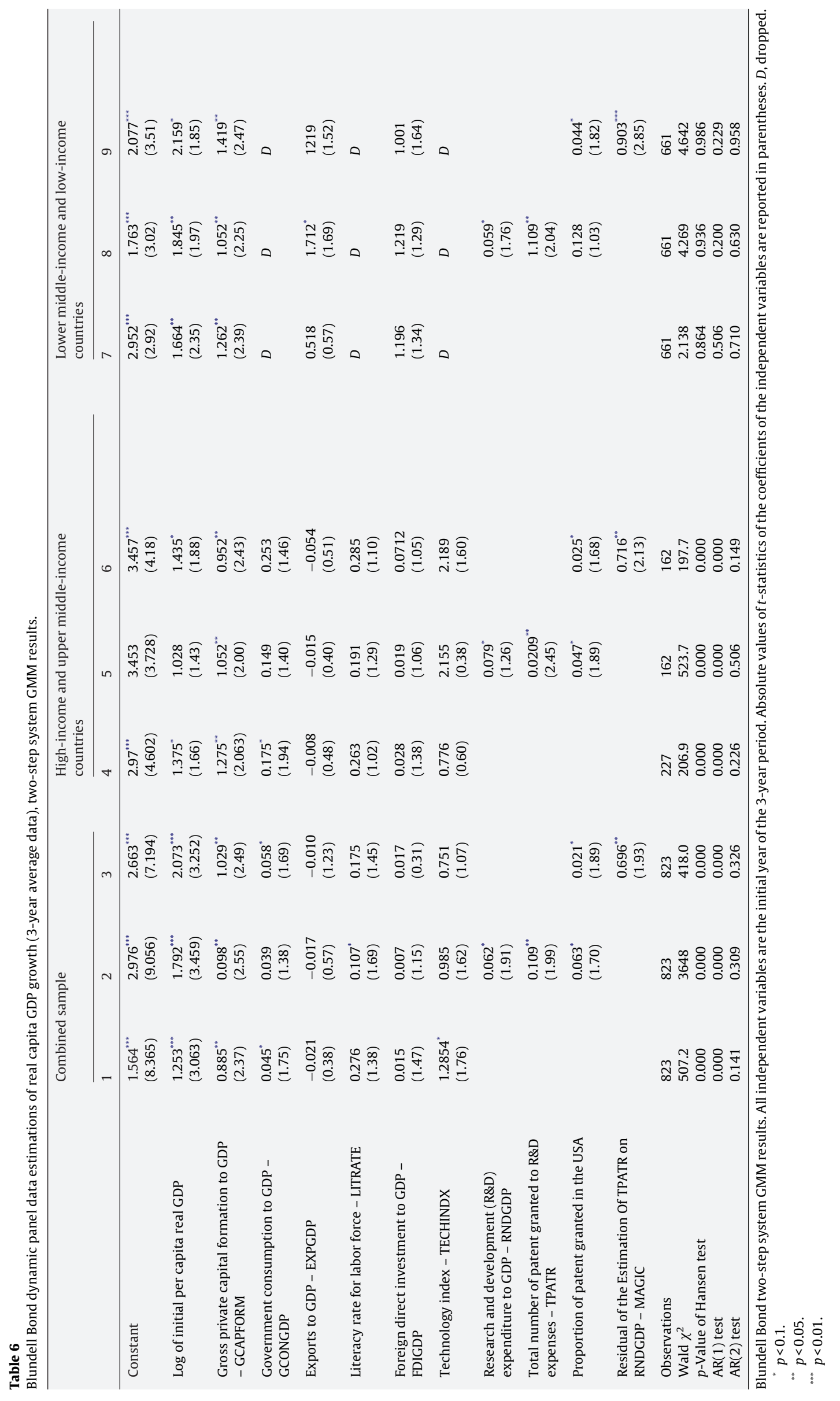


effect. As the OLS annual and 3-year equations show (Table 4), the convergence effect is mostly significant although it is insignificant in the high- and upper middle-income country sub-sample. In both annual and 3-year average OLS estimations, Gross Capital Formation (GCAPFORM) and FDIGDP variables are consistently statistically significant. The openness or Export variable is positive and statistically significant in a few of the regressions.

Coming to our hypotheses, the first hypothesis proposed that innovation activities are important for firms' economic growth. This is seen by looking at the second model in each subset of the data (i.e., Models 2, 5, and 8 in each of the two tables). As shown in the tables, the ratio $R E D$ Expenditures to GDP has a positive and statistically significant relation with growth in per capita GDP. Likewise the ratio of Total Patents Granted to Total RED Expenditures is positive and statistically significant, indicating an association with GDP growth. The first measure, as discussed above, can be considered an innovation input measure, while the second measure may be considered an innovation output or innovation efficiency measure. Thus we see that innovation input and output are associated with GDP growth virtually across the board. Although coefficient estimates and confidence levels vary somewhat from equation to equation and across tables, the overall picture is supportive of the fact that innovation does matter in explaining economic growth. Turning to coefficients on the measures of R\&D and innovation variables, we see that $R N D G D P$ has a relatively small coefficient, while TPATR has a larger coefficient that is positive and statistically significant.

The second hypothesis has to do with whether quality innovation output matters. This is shown in the same models as above, plus the third model of each subset of the data (i.e., Models 3, 6, and 9 in each of the two tables). As discussed previously, we take the Proportion of Patents Granted in the USA as a kind of patent quality measure at the country level. Overall, there appears to be some support for this hypothesis: the coefficient of our quality measure is often, but not always, positive and statistically significant. However, when we add the variable MAGIC, which represents a kind of factor in innovative output unexplained by R\&D spending, the Proportion of Patents Granted in the USA always becomes statistically insignificant. The overall interpretation offers support for Hypothesis 2, that quality innovation output leads to even higher growth than average innovation output.

The GMM annual regressions (Table 5) as well as the 3-year average estimations (Table 6 ) suggest that the results are consistent with the OLS estimations although the relative importance, i.e., the statistical significance of the coefficients of our key independent variables are relatively less robust. As shown in the combined sample (columns 1-3), both RNDGDP and TPATR show a statistically significant positive impact on economic growth. Additionally, when the MAGIC variable is substituted as the alternative innovation variable, we still find a strong positive influence of innovation. When the estimations are done separately on upper- and lowerincome sub-samples, we see the magnitude and strength of the results are similar to the combined results except that the lowerincome country coefficients of the focused variables are more statistically significant. ${ }^{6}$

In sum, our results show that after controlling for the year and country-specific effects, there exists a strong, positive link between innovative success and economic growth.

Robustness tests. In order to boost confidence in our results, we performed various robustness tests. The robustness tests address several important issues. First, we investigated whether the results were consistent if we examined different sub-samples, such as

\footnotetext{
${ }^{6}$ We should add that in estimating the GMM for this lower-middle-income and lower-income country sub-sample, the program automatically dropped some variables from the regression.
}

whether the country is known as an "emerging" or a "developed" country market. We used nominal R\&D expenditures instead of real expenditures. We also added some additional independent variables used by some authors in the growth literature as control variables, e.g., bank credit to private sector as a proportion to GDP and also private sector to GDP ratio. In these cases, we found strong support for our hypotheses. Moreover, we substituted the quality of innovation variable - proportion of patents granted in the USA - with a new proxy: total number of forward citations of the total granted patents. We could not get consistent data for all sample countries for all sample years. However, we still found statistically significant association between our independent variables and the dependent variable that supports the two hypotheses.

We also undertook an investigation of "macro gaps" or gaps in national innovation systems that may confound US patenting with quality. The argument goes that poor institutional support in the home country may drive firms to patent in the US not because quality is so high but that home protection is so poor that a high percentage of patents are filed in the US. First, we examined the applications from non-US companies in the US and found that (1) they were from the most developed countries, and (2) they were also related to the amount of trade they have with the US. We also conducted two additional regression analyses, the first was a simultaneous equation (SUR) analysis with annual growth rate per capita GDP a function of lagged growth, gross capital formation, government consumption to GDP, exports to GDP, literacy rate, FDI to $G D P$, technology index, RED Expenditures to GDP, total patents per million dollars of RED, and percentage granted in the US; while percentage granted in the US is simultaneously a function of deviation from US GDP growth, exports to GDP, literacy rate, technology index, and $R E D D$ Expenditures to GDP. In such specifications, the deviation from US GDP growth is negatively related to percentage granted in the US, meaning that rapidly growing (developing) countries tend to have a lower percentage patented in the US, not a higher percentage (results available from authors). We observed the same results with the same functional form but using a 2SLS specification. We therefore conclude that our results are not being totally driven by a macro-gap story, but more likely a direct commercial gain (e.g., exports or US sales) story.

We also undertook an analysis of the role of patent stock on our results. For example, it could be that the MAGIC variable represents not a knowledge spillover, but rather a "momentum" effect of prior output. In other words, when a country has a higher unexplained output given their R\&D investments, it could be because of all the prior research done in the past and not because current knowledge is diffusing rapidly. Thus we reran all of our analyses, with patent stock included in the first stage in which we generated the MAGIC variable. In results available from the authors, we find that indeed although the patent stock is statistically significant in the regression that produces MAGIC, the variable MAGIC in the subsequent regressions loses none of its power.

Therefore, in all instances examined, there were no alarming qualitative changes to our results or interpretations thereof.

\section{Discussion and conclusions}

In summary, we find that both the quantity of inventive activity, as well as its quality, are associated with economic growth. Based on the OLS results, we may be able to conclude that countries that have higher levels of patenting activity - as well as those whose patents primarily are filed in the US - tend to be the countries with higher growth rates. Furthermore, it seems based on panel regression and country fixed effects that countries that increase the level of patenting activity - or increase the proportion filed in the US tend to be associated with increases in the growth rate. Thus we find results consistent with both our hypotheses. 
Table 7

Granger causality tests.

We wanted to investigate the direction of causality between GDP per capita growth with various patent quality measures to see whether quality has an impact on growth or higher growth causes corporations to be produce higher quality innovations. To this end, we employed the Granger-Sims causality framework (Granger, 1969; Sims, 1972) and estimated the regressions in the following way. We first tried to determine if USAR in the previous year has an impact on the GDPPCGR variable in the current year: Similarly, we replace USAR with MAGIC.

$\mathrm{GDPPCGR}_{t}=f\left(\mathrm{GDPPCGR}_{t-1}, \mathrm{GDPPCGR}_{t-2}\right)+e_{i}$

GDPPCGR $_{t}=f\left(\right.$ GDPPCGR $_{t-1}$, GDPPCGR $\left._{t-2}, \ldots \mathrm{USAR}_{t-2}\right)$

GDPPCGR $_{t}=-0.0215(1.23)+0.1813$ GDPPCGR $_{t-1}(6.04)+0.1526 \operatorname{GDPPCGR}_{t-2}(3.28), R^{2}=0.0379$

GDPPCGR $_{t}=-0.0194(1.38)+0.1659$ GDPPCGR $_{t-1}(5.87)+0.137 \operatorname{GDPPCGR}_{t-2}(3.09)+0.0135 \operatorname{USAR}_{t-1}(2.11), R^{2}=0.0478$

The coefficients and $t$-statistics (in parenthesis) reported above give us a perspective whether USAR was causing growth or whether growth was important in determining quality of innovation. In this case we were not able to reject the null hypothesis that the USAR had no explanatory power with regards to GDPPCGR. In fact, we found that the quality variable in year $t-1$ was significant at the $5 \%$ level. We performed similar regressions using the other alternative quality variable (MAGIC). The results were reasonably similar, although we obtained the stronger $t$-statistics $(t=5.42$ significant at the $1 \%$ significance level).

We then reversed the question and tried to determine whether current or past GDPPCGR performance has an impact on USAR. We estimated the following regression:

$\mathrm{USAR}_{t}=f\left(\mathrm{USAR}_{t-1}, \mathrm{USAR}_{t-2}, \mathrm{GDPPCGR}_{t-1}\right)+e_{i}$

We obtained the following results:

$\mathrm{USAR}_{t}=0.0334(1.70)+0.015 \mathrm{USAR}_{t-1}(1.96)+0.0053 \mathrm{USAR}_{t-1}(1.76)+0.046 \mathrm{GDPPCGR}_{t-1}(1.62), R^{2}=0.1354$

The significant $t$-statistics on GDPPCGR ${ }_{t-1}$ suggests that past performance also has some marginal affect (coefficient $0.046, t=1.63$ significant at $11 \%$ level) on quality measure even after past quality measures are taken into consideration. When we substituted USAR with MAGIC as a quality variable, the results were not statistically significance at all.

Finally, we performed additional tests (not reported in the text) by incorporating a future period $(t+1)$ along with the past periods $(t-1, t-2)$ and re-estimated the above-mentioned regressions. We found that in all cases the causality seems to run in both directions except it is significantly stronger and statistically more significant in the direction from quality of innovation to growth. The overall evidence associated with the Granger-Sims tests suggests that future studies should consider more careful analysis by including a higher number of lagged values.

An important limitation of this study, of course, is the general equation of patents with innovation and the use of various derivative measures based on such patents to infer innovation level. This is a relatively common practice in the literature at multiple levels of analysis (e.g., Ahuja and Katila, 2001; Bottazzi and Peri, 2003; Maurseth and Verspagen, 2002) because (1) patents do indeed represent inventive output, and such output is intended to (usually, see below) be commercialized; (2) detailed statistics have been collected and kept over the years; and (3) patents are in general costly to obtain and defend, implying some kind of financial benefit in return. Thus if innovation = invention + exploitation, as Roberts (1988) has proposed, it does appear that the inventive output plus the intention and incentive to commercialize (exploit) would lead to something akin to innovation.

However, there are indeed several problems with equating patents and innovation, which we must acknowledge. Griliches (1990, p. 1669) pointed out several, for example, "Not all inventions are patentable, not all inventions are patented,..." The first of these refers to the fact that there are many innovations that do not qualify for legal patent protection (e.g., software products in many countries of the world, or organizational innovations such as adoption of cross-functional teams). The second is that there are many innovations that are never patented (and instead kept as a secret), even though they could be patented from a legal point of view (Cohen et al., 2000). Another third issue hinted at above is that firms may use patents to "block" other companies from commercializing an invention rather than to commercialize it themselves. A fourth problem may be the different incidences of patenting behavior across different industries (e.g., high propensity in chemicals compared to lower incidence in software or white goods).

Due to the issues described above, patent statistics may be considered "noisy" and imperfect proxies for innovation. However, many scholars have concluded that despite their limitations and despite the "noise," patents are acceptable for studying innovation and in fact are often associated with better measures of innovation in the limited number of cases where such data are available. For a more detailed discussion on the advantages and disadvantages of using patent data in innovation studies, see Griliches (1990),
Freeman and Soete (1997, pp. 112-120) and Tid and Bessant (2009, pp. 555-560)

Regarding the dependent variable, we chose GDP growth because it seems this is the most important variable considered by policymakers. However, in future research we should also consider total factor productivity or other national performance measures, and perhaps control for educational levels, political risk, and possibly levels of government debt. ${ }^{7}$

Another question the results raise is one of reverse causality. That is, how do we know that more patents lead to economic growth, rather than countries with high economic growth leads to firms that have more profits to invest, which they then spend on patenting activities? Or it could be that patenting in the US actually leads to higher returns than patenting in the home country due to the size of the US market, which leads to more profits for the firm, leading to growth in the home country (i.e., it is not a question of quality at all, more of path dependency). These questions are difficult to tease apart empirically but in an ad hoc analysis, we examined a Granger-Sims causality test (Granger, 1969; Sims, 1972) as shown in Table 7. The results of this analysis indicate that, while we cannot completely rule out the possibility of growth leading to higher quality patents, the preponderance of evidence leads us to believe that on average, higher quality patenting precedes growth.

Another question that this research raises is related to the locus of the inventive activity itself. For example, outsourcing has been a hot topic in the early 2000s. Is it possible that a country may have much innovative activity but the economic growth occurs outside that country? Put another way, how do we know that if a multinational firm has R\&D centers in various countries, the benefits flow only to the country in which the firm is headquartered? Thus another limitation of our study is the inability to tease apart a more fine-grained tracing of patenting and economic behavior. However, for a broad picture, the results seem remarkably consistent and clear.

\footnotetext{
7 We would like to thank Pierpaolo Parrotta and Marianna Marino for these suggestions.
} 
The public policy implications of the results are also evident. While Lerner (2002) warns that strengthening intellectual property protection does not do much to spur patent applications in countries with already advanced systems, it would seem logical that countries with weaker systems could get many more applications by strengthening their intellectual property rights. Of course, simply applying for more patents does not necessarily translate into either more patents granted or higher quality patents. Certainly, a country should not lower its standards when it comes to granting patents. Maybe governments should subsidize the fees or even award prizes for successfully applying for patents in the US? The standards in the US should remain relatively constant over any short time period so the overall quality level should remain relatively constant. However, the increased innovation activity to get past the application hurdles and perhaps win the prize may lead to higher economic growth in the country.

Thus it would seem that, based on the results of this study, government schemes that attempt to raise the level of R\&D spending in a country may be only one of several R\&D policy tools associated with increasing economic growth. We may consider it to be part of a multi-pronged approach that includes RNDGDP as one piece. As we know, the goal of most economies is not more R\&D spending per se, but rather a higher rate of growth and national wealth that is presumed to result from such investment.

As Griliches (1990, p. 1669) also observed, "the inventions that are patented differ greatly in 'quality' in the magnitude of inventive output associated with them." Regarding such quality, while RNDGDP was certainly statistically significant and associated with growth, we cannot discount the statistical significance of MAGIC as well. There could be several institutional factors at play that go beyond R\&D spending relating to employee mobility (and thus spillovers). On the legal front, these institutional factors could include labor law, taxation law, immigration law, and intellectual property law (especially governing trade secrets). Also importantly entering into this legal equation could be contract law, which has to do with the employment relation, non-compete, or restraint of trade laws. For example, in jurisdictions in which noncompete clauses are less enforceable, one would expect to see more employee mobility and thus more spillovers (van Caenegem, 2005). Other factors might include prevalence of trade fairs or technical conferences, availability of venture capital (not from a financial point of view but a knowledge leakage point of view), prevalence of crowdsourcing over the Internet, strength of university-industry ties, and/or cultural norms for exchanging what could be proprietary information. Thus a whole host of institutions and culture that affect knowledge sharing and therefore spillovers and therefore the ability to generate more growth per dollar spent on R\&D. So as our final policy prescription/question: perhaps national governments should also focus some of their attention on raising the "magic in the air"?

\section{Acknowledgements}

The authors would like to thank Marco Ceccagnoli, Dominique Foray, W. Curt Hunter, Stéphane Lhuillery, Marianna Marino, Pierpaolo Parrotta, Grid Thoma, Editor Fumio Kodama, the two anonymous Research Policy referees, and participants at the Associazione Guido Carli/Fondazione Cesifin Alberto Predieri Fifth Florence Colloquium on "Money, Derivatives, Innovation, and Growth," for helpful comments on prior versions of this paper.

\section{References}

Afuah, A., Tucci, C.L., 2003. Internet Business Models and Strategies, 2nd edition. McGraw-Hill, New York.
Aghion, P., Howitt, P., 1992. A model of growth through creative destruction. Econometrica 60 (2), 323-351.

Ahuja, G., Katila, R., 2001. Technological acquisitions and the innovation performance of acquiring firms: a longitudinal study. Strategic Management Journal $22,197-220$.

Arellano, M., Bover, O., 1995. Another look at the instrument variable estimation of error-components models. Journal of Econometrics 68, 29-51.

Audretsch, D.B., 1995. Innovation and Industry Evolution. MIT Press, Cambridge.

Audretsch, D.B., Feldman, M.P., 1996. R\&D spillovers and the geography of innovation and production. American Economic Review 86 (3), 630-640.

Barro, R.J., Levine, R., 1991. Economic growth in a cross-section of countries. Quarterly Journal of Economics 106 (2), 407-443.

Bayoumi, T., Coe, D.T., Helpman, E., 1999. R\&D spillovers and global growth. Journal of International Economics 47 (2), 399-428.

Blundell, R., Bond, S., 1998. Initial conditions and moment restrictions in dynamic panel data model. Journal of Econometrics 87, 115-143.

Bond, S.R., 2002. Dynamic panel data models: a guide to micro data methods and practice. Portuguese Economic Journal 1, 141-162.

Bottazzi, L., Peri, G., 2003. Innovation and spillovers in regions: evidence from European patent data. European Economic Review 47 (4), 687-710.

Cameron, G., 1998. Innovation and growth: a survey of the empirical evidence. Working Paper. Nuffield College, Oxford University.

Coe, D.T., Helpman, E., 1995. International R\&D spillovers. European Economic Review 39, 859-887.

Cohen, W.M., Nelson, R.R., Walsh, J.P., 2000. Protecting their intellectual assets: appropriability conditions and why US manufacturing firms patent (or not). NBER Working Paper 7752. National Bureau of Economic Research.

Duguet, E., MacGarvie, M., 2005. How well do patent citations measure flows of technology? Evidence from French innovation surveys. Economics of Innovation and New Technology 14 (5), 375-393.

Fagerberg, J., 1994. Technology and international differences in growth rates. Journal of Economic Literature 32 (3), 1147-1175.

Francis, B., Hasan, I., Wang, H., 2007. The role of venture capital on innovation, new business formation and economic growth. Working Paper. RPI Lally School of Management \& Technology.

Freeman, C., Soete, L., 1997. The Economics of Industrial Innovation. MIT Press, Cambridge.

Goel, R.K., Ram, R., 1994. Research and development expenditures and economic growth: a cross-country study. Economic Development and Cultural Change 42 (2), 403-411.

Granger, C.W.J., 1969. Investigating Causal Relations by Econometric Models and Cross-spectral Methods. Econometrica 37 (3), 424-438.

Griliches, Z., 1980. R\&D and the productivity slowdown. American Economic Review 70 (2), 343-348.

Griliches, Z., 1990. Patent statistics as economic indicators: a survey. Journal of Economic Literature 28 (4), 1661-1707.

Griliches, Z., 1992. The search for R\&D spillovers. Scandinavian Journal of Economics 94 (Suppl.), 29-47.

Griliches, Z., Mairesse, J., 1986. R\&D and productivity growth: comparing Japanese and US manufacturing firms. European Economic Review 21 (1/2), 89-119.

Grossman, G.M., Helpman, E., 1994. Endogenous innovation in the theory of growth. Journal of Economic Perspectives 8 (1), 23-44.

Hall, B., Jaffe, A., Trajtenberg, M., 2001. The NBER Patent Citations Data File: Lessons, Insights and Methodological Tools. NBER Working Paper No. 8498. National Bureau of Economic Research.

Harhoff, D., Hoisl, K., Webb, C., 2008. European patent citations-how to count and how to interpret them? Working paper. University of Munich, CEPR and OECD.

Jaffe, A.B., Trajtenberg, M., 1999. International knowledge flows: evidence from patent citations. Economics of Innovation and New Technology 8 (1/2), 105-136.

Jaffe, A.B., Trajtenberg, M., Henderson, R., 1993. Geographic localization of knowledge spillovers as evidenced by patent citations. Quarterly Journal of Economics 108 (3), 577-598.

King, R.G., Levine, R., 1993. Finance and growth: Schumpeter might be right. Quarterly Journal of Economics 108 (3), 717-737.

Kirchhoff, B.A., 1994. Entrepreneurship and Dynamic Capitalism: The Economics of Business Firm Formation and Growth. Praeger, Westport, CT.

Kirchhoff, B., Catherine, A., Newbert, S.L., Hasan, I., 2007. The influence of university R\&D expenditures on new business formations and employment growth. Entrepreneurship Theory and Practice 31, 543-559.

Knack, S., Keefer, P., 1995. Institutions and economic performance: cross-country testing using alternative institutional measures. Economics and Politics 7 (3), 207-227.

Kortum, S., Lerner, J., 1999. What is behind the recent surge in patenting? Research Policy 28 (1), 1-22.

Lerner, J., 2002. Patent protection and innovation over 150 years. NBER Working Paper W8977. National Bureau of Economic Research.

Levine, R., Loayza, N., Beck, T., 2000. Financial intermediation and growth: causality and causes. Journal of Monetary Economics 46 (1), 31-77.

Lucas, R.E., 1988. On the mechanics of economic development. Journal of Monetary Economics 22, 3-42.

Mansfield, E., 1980. Basic research and productivity increase in manufacturing. American Economic Review 70 (5), 863-873.

Maurseth, P.B., Verspagen, B., 2002. Knowledge spillovers in Europe: a patent citation analysis. Scandinavian Journal of Economics 104 (4), 531-545.

Nelson, R.R. (Ed.), 1993. National Systems of Innovation. Oxford University Press, New York. 
Roberts, EB, 1988. What we've learned: managing invention and innovation. Research Technology Management 31 (January-February), 11-29.

Romer, P.M., 1986. Increasing returns and long-run growth. Journal of Political Economy 94 (5), 1001-1037.

Romer, P.M., 1990. Endogenous technological change. Journal of Political Economy 98 (5), S71-S102.

Rousseau, P.L., Wachtel, P., 2000. Equity markets and growth: cross-country evidence on timing and outcomes, 1980-95. Journal of Banking and Finance 24 1933-1957.

Schmookler, J., 1966. Invention and Economic Growth. Harvard University Press, Cambridge.

Schumpeter, J.A., 1932. Capitalism, Socialism, and Democracy. Harper and Brothers, New York.

Shapiro, C., 2001. Navigating the patent thicket: cross-licenses, patent pools, and standard setting. In: Jaffe, A.B., Lerner, J., Stern, S. (Eds.), Innovation Policy and the Economy, vol. 1. MIT Press, Cambridge, pp. 119-150.

Sims, C.A., 1972. Money, income, and causality. American Economic Review 62 (4), $540-552$.
Stokey, N.L., 1995. R\&D and economic growth Review of Economic Studies 28 (4) $1661-1707$

Teece, D.J., 1986. Profiting from technological innovation. Research Policy 15 (6), 285-305

Tid, J., Bessant, J., 2009. Managing Innovation: Integrating Technological, Market and Organizational Change. Wiley, New York.

Tucci, C.L., Kaufman, A., Wood, C.H., Theyel, G., 2005. Collaboration and teaming in the software supply chain. Supply Chain Forum 6 (1), 16-28.

United States Code, Title 35, Section 101 (Patent Act of 1952).

van Caenegem, W., 2005. Inter-firm migration of tacit knowledge: law and policy. Prometheus 23 (3), 285-306.

Wachtel, P., 2001. Growth and finance: what do we know and how do we know it? International Finance 4, 335-362.

Wennekers, S., 1999. Linking entrepreneurship and economic growth. Small Business Economics 13 (1), 27-55.

Windmeijer, F., 2005. A finite sample correction for the variance of linear efficient two-step GMM estimators. Journal of Econometrics 126, 25-51. 